\title{
Effect of Polyolefin Film and Light Transition Film on the Growth of Lettuce
}

\author{
Lei $\mathrm{Xu}^{1}$, Lijun $\mathrm{Yu}^{1}$, Xizhi Jiang ${ }^{1}$, Yongfu Zhao ${ }^{1} \&$ Liru Xia $^{1}$ \\ ${ }^{1}$ Institute of Agricultural Facilities and Equipments, Jiangsu Academy of Agricultural Sciences, Nanjing, China \\ Correspondence: Liru Xia, Institute of Agricultural Facilities and Equipments, Jiangsu Academy of Agricultural \\ Sciences, Nanjing 210014, China. E-mail: xlrjaas@126.com
}

Received: January 10, 2018

Accepted: March 21, $2018 \quad$ Online Published: April 15, 2018

doi:10.5539/jas.v10n5p379

URL: https://doi.org/10.5539/jas.v10n5p379

The research is financed by Key Lab of Food Quality and Safety of Jiangsu Province-State Key Laboratory Breeding Base and Independent Innovation of Agricultural Sciences in Jiangsu Province CX(16)1002.

\begin{abstract}
In this study, effects of polyolefin (PO) film and light transition film on the growth of lettuce were investigated compared with ethylene-vinylacetate (EVA, antifogging, no drops and longevity type) film covering. Results showed that the temperature and humidity in greenhouse covered with PO film and light transition film were significantly increased. The average temperature in the greenhouse was $4{ }^{\circ} \mathrm{C}$ higher than outdoor temperature. The average illumination intensity in the greenhouse covered with PO film was $293.22 \mu \mathrm{mol} \mathrm{m}^{-2} \mathrm{~s}^{-1}$, light transmittance was $80.37 \%$, the average illumination intensity in the greenhouse covered with EVA film was $193.04 \mu \mathrm{mol} \mathrm{m} \mathrm{s}^{-2}$, light transmittance was 52.91\%. Compared with the common film, light transmittance of the PO film was significantly increased. Light transition film increased the chlorophyll content of lettuce by changing the element of the sunlight and increased production of vegetables. PO film and light transition film display a good application prospective in the production of vegetables.
\end{abstract}

Keywords: PO film, light transition film, lettuce, quality, production

\section{Introduction}

The covering material has an important influence on the temperature and light environment in the greenhouse and plays an important role in the process of vegetable growth (Ali Dadfar, Alemzadeh, Reza Dadfar, \& Vosoughi, 2011). Nowadays, there are many kinds of films being developed both at home and abroad. Those films have different function and performance. PO (Polyolefin) film is a kind of agricultural film composed of raw materials suchas polyethylene and ethylene-vinyl acetate and auxiliaries. PO film has the characteristics of high strength, strong anti-aging properties and high transmittance. It can be used continuously for 5-6 years (Avérous, 2004). The useless film is easy to handle. It can be used as a renewable resource and does not emit harmful gases when burned. Light transition film is a kind of film which can change the quality of light. The photosynthesis of crops mainly focuses on the absorption of blue and red light of the solar spectrum. The blue and red lights are benefit to the growth of crops, but green and near ultraviolet light is not. The light transition film can translate green and near ultraviolet light to red light, change the element of sunlight, strength light quality, extend the photosynthesis period, improve the utilization rate of solar energy, promote crop precocious and improve the quality of the crops (Balau, Lisa, Popa, Tura, \& Melnig, 2004). In the morning, evening, rain and snow and other weak light weather, the film still can absorb diffuse reflection light, carry on effective photosynthesis. It still can improve the production, enhance the photosynthesis of crops in the greenhouse, reduce plant diseases and insect pests, so as to shorten the crops mature period, and improve the yield of crops (Bonilla, Fortunati, Vargas, Chiralt, \& Kenny, 2013).

In this study, effects of PO film and light transition film covering on greenhouse on the growth of lettuce were investigated compared with ethylene-vinylacetate film and provided a reference for the application and promotion of the PO film and the light transition film in China. 


\section{Experiment}

\subsection{Materials}

Vegetable for the experiments is lettuce. Films for the experiments are PO film, light transition film and EVA film.

\subsection{Methods}

In this study, the greenhouses covered by the PO film and the light transition film were treated compared with the greenhouse covered by the EVA film. The whole experiment area was divided to twelve departments and each department was 1.2 meters wide and 2.5 meters long. The plant spacing was $15 \mathrm{~cm}$ and the row spacing was $30 \mathrm{~cm}$. The gap surrounding each department was $100 \mathrm{~cm}$ and each department was $150 \mathrm{~cm}$ apart. Before the lettuce was transplanted, the temperature was increased to accelerate the growth. Timely replanting of dead seedlings. The same water, fertilizer, insect repellent and other management measures are adopted in each department.

\subsection{Instruments}

The light meter for the experiments to measure the illumination intensity was the LI-250A light meter and the manufacturer was the LI-COR company. The chlorophyll meter for the experiments to measure the chlorophyll content was SPAD-502PLUS chlorophyll light and the manufacturer was the KONICA MINOLTA company.

\subsection{Characterization}

\subsubsection{Temperature and Light Data Collection}

The temperature and the illumination intensity in and out of the greenhouse was measured twice everyday regularly. The photosynthetic intensity was measured after 7 days and 1 time per 7 days.

\subsubsection{The Growth and the Production of the Lettuce}

After 7 days, the height of the plant was measured, 1 time per 7 days; after harvest, the fresh weight of the ground part, fresh weight of the edible part and yellow leaves were measured.

\section{Analysis and Discussion}

\subsection{Effects of PO Film and Light Transition Film on the Average Temperature and Humidity in the Greenhouse}

POfilm, light transition film and ordinary EVA film increased the temperature in the greenhouse. The daily average temperature of the greenhouse covered by PO film, light transition film and EVA film maintained $12{ }^{\circ} \mathrm{C}$ compared with $8{ }^{\circ} \mathrm{C}$ outside the greenhouse. The daily average humidity of the greenhouse covered by PO film, light transition film and EVA film was $65 \%$ compared with $50 \%$ outside the greenhouse. It shows that the effect of PO film and light transition film on the daily average temperature and humidity is not significant. PO film, light transition film and EVA film have the same heat preservation effect.

\subsection{Effects of PO Film and Light Transition Film on the Average Illumination Intensity in the Greenhouse}

Figure 1 shows the the illumination intensity comparison of the greenhouse covered by PO film, light transition and ordinary EVA film and outdoors. The transmittance of PO film is the highest, and the transmittance of the light transition film is the lowest. The average illumination intensity of the greenhouse covered by PO film was $293.22 \mu \mathrm{mol} \mathrm{m}^{-2} \mathrm{~s}^{-1}$. The outdoor average illumination intensity was $364.8 \mu \mathrm{mol} \mathrm{m}^{-2} \mathrm{~s}^{-1}$, and the transmittance of PO film was $80.37 \%$. It shows the advantages of high transmittance of PO film. The light transition can translate the green and near ultraviolet light in the sunlight which is not good to the growth of the plant to the red light which is beneficial to the plant, so the transmittance of the light transition decreased. 


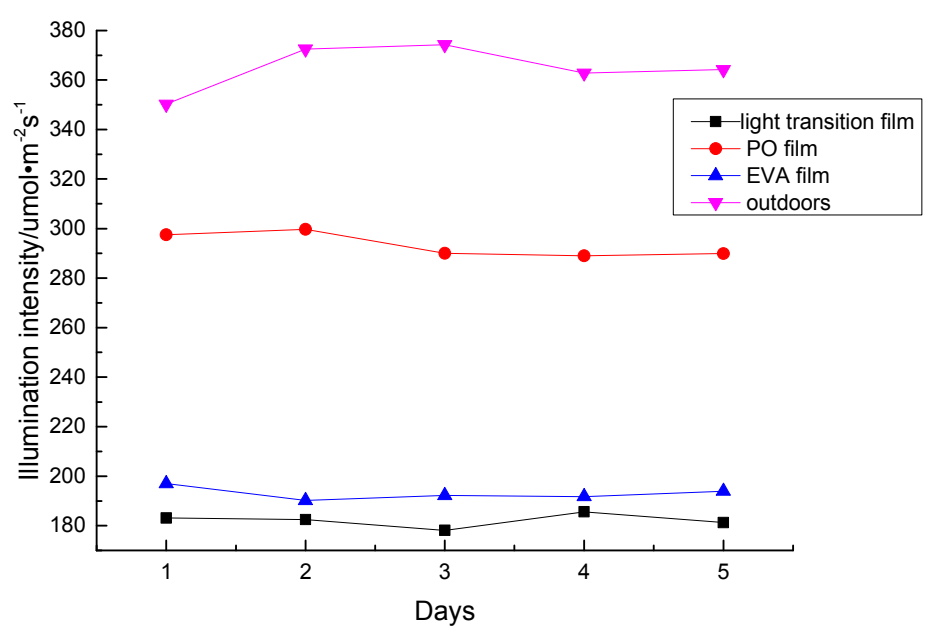

Figure 1. The illumination intensity comparison of the greenhouse covered by PO film, light transition and ordinary EVA film and outdoors

\subsection{Effects of PO Film and Light Transition Film on the Chlorophyll Content of Plant in the Greenhouse}

Figure 2 shows the effects of light transition film and ordinary EVA film on the chlorophyll content of plant in the greenhouse. Figure 3 shows the effects of PO film and ordinary EVA film on the chlorophyll content of plant in the greenhouse (Epure, Griffon, Pollet, \& Avérous, 2011). From the figures, the chlorophyll content in lettuce in the greenhouse covered by the light transition film significantly increased, the light transition film filterred out the green light and near-ultraviolet light that is harmful to the growth of lettuce and improved the photosynthetic rate, thus improving the chlorophyll content in lettuce and improving the utilization rate of sunlight. The chlorophyll content of lettuce in the greenhouse covered by PO film is a little higher than the common film (Correlo, Boesel, Bhattacharya, Mano, Neves, \& Reis, 2005). It shows that the high transmittance has a positive effect on the improvement of chlorophyll content in lettuce.

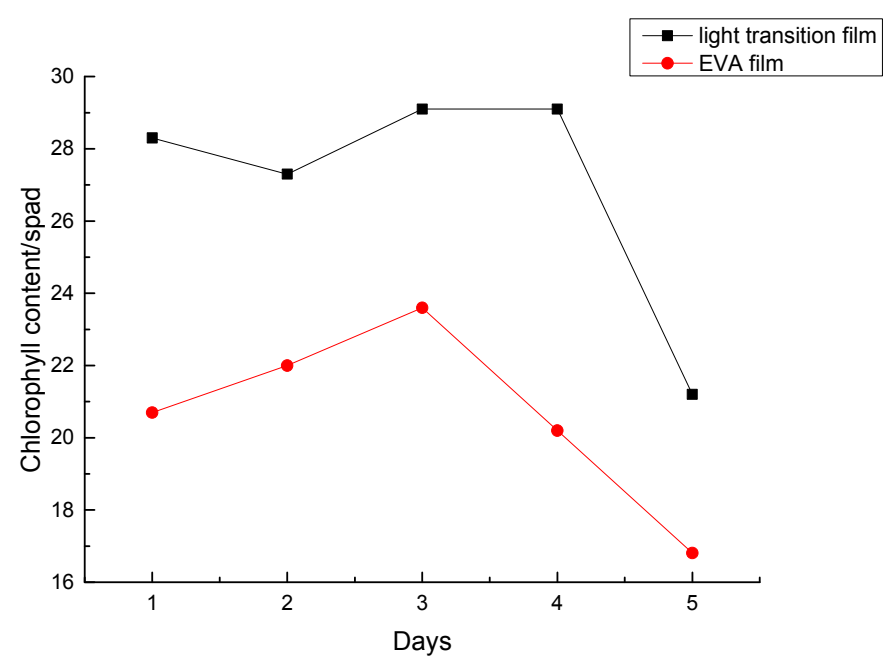

Figure 2. Effects of light transition film and ordinary EVA film on the chlorophyll content of plant in the greenhouse 


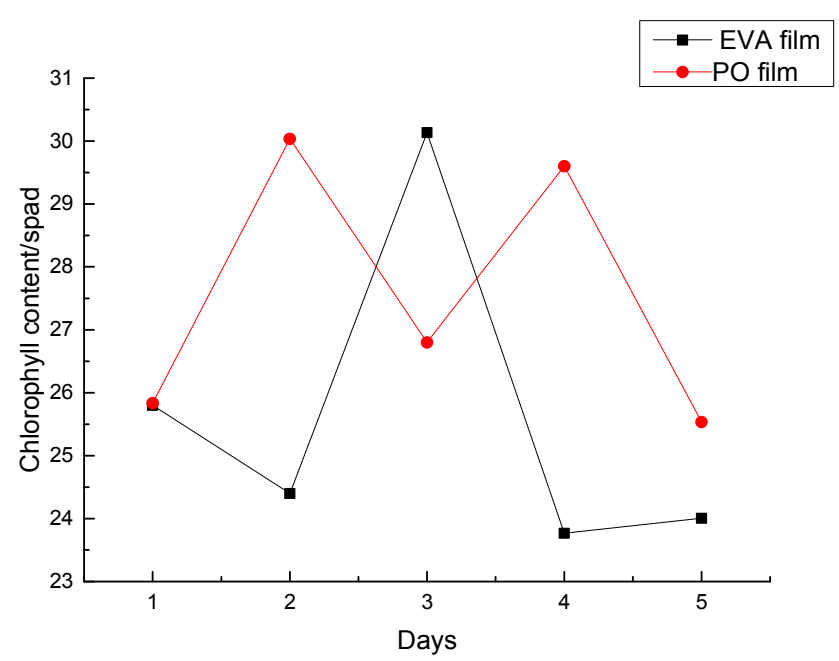

Figure 3. Effects of PO film and ordinary EVA film on the chlorophyll content of plant in the greenhouse

\subsection{Effects of PO Film and Light Transition Film on the Growth and the Production of Plant in the Greenhouse}

Figure 4 shows that the lettuce in the greenhouse covered by the PO film performed the best among three kinds of films. The number of the yellow leaves was significantly decreased. The number of the edible leaves is $1 \%$ higher than ordinary EVA film (Domard \& Rinaudo, 1983). The number of the yellow leaves and the edible leaves in the greenhouse covered by the light transition film is lower than the number in the greenhouse covered by EVA film. The reason is the light transition film translate the unuseful light of the sun to red and high percent of red light improved the quality of lettuce. However, the production of lettuce decreased because of the low transmittance (Dutta, Tripathi, Mehrotra, \& Dutta, 2009).

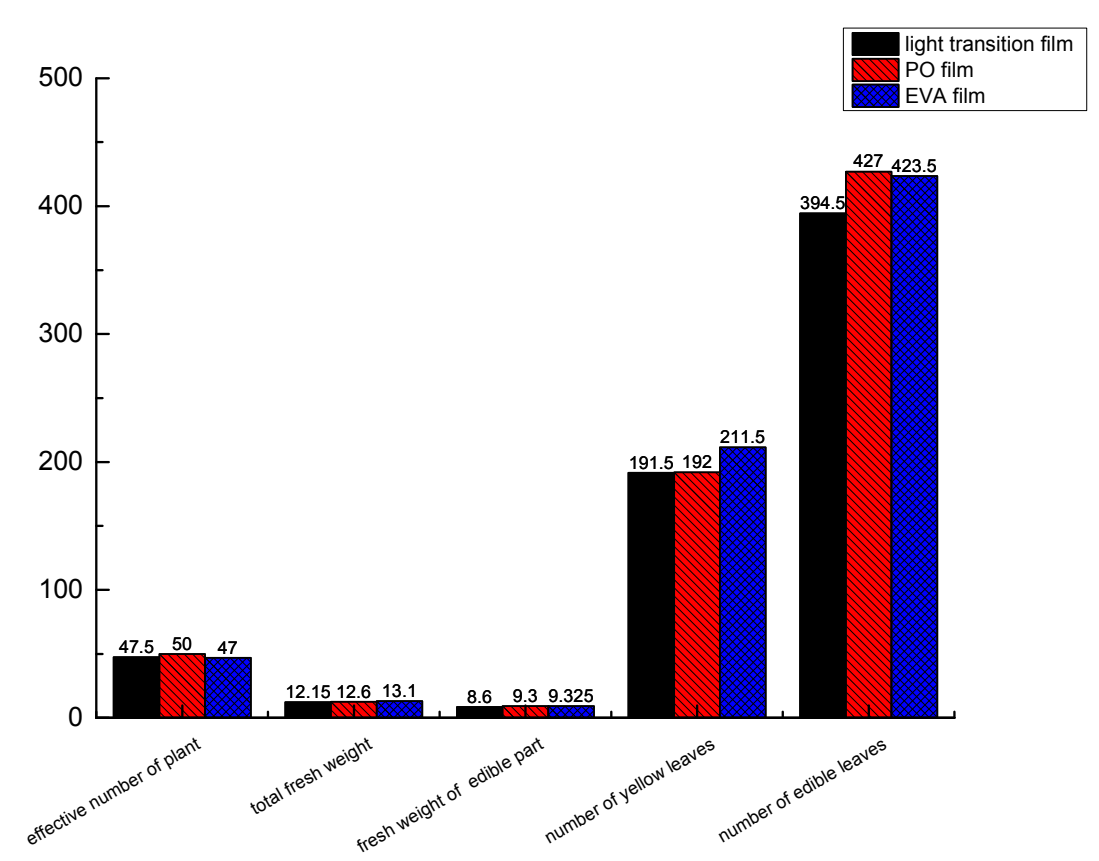

Figure 4. Effects of PO film and light transition film on the growth and the production of plant in the greenhouse

\section{Conclusion}

The illumination intensity in the greenhouse covered by PO film is obviously improved, and it can promote the growth of plants (Hernandez-Izquierdo \& Krochta, 2008). The illumination intensity is not high in the 
greenhouse covered by light transition film, but by translating green and near ultraviolet light to red light, light transition films change the element of sunlight, strength light quality, extend the photosynthesis period, improve the utilization rate of solar energy, promote crop precocious, improve the quality of the crops (Leceta, Guerrero, \& de la Caba, 2013). Therefore, light transition film and PO film display a good application prospective in the production of vegetables. The present problem is how to combine the advantages of PO film and light transition film, and it deserves further research.

\section{References}

Ali Dadfar, S. M., Alemzadeh, I., Reza Dadfar, S. M., \& Vosoughi, M. (2011). Studies on the oxygen barrier and mechanical properties of low density polyethylene/organoclay nanocomposite films in the presence of ethylene vinyl acetate copolymer as a new type of compatibilizer. Materials \& Design, 32(4), 1806-1813. https://doi.org/10.1016/j.matdes.2010.12.028

Avérous, L. (2004). Biodegradable multiphase systems based on plasticized starch: A review. Polymer Reviews, 44(3), 231-274. https://doi.org/10.1081/MC-200029326

Balau, L., Lisa, G., Popa, M., Tura, V., \& Melnig, V. (2004). Physico-chemical properties of chitosan films. Central European Journal of Chemistry, 2(4), 638-647. https://doi.org/10.2478/BF02482727

Bonilla, J., Fortunati, E., Vargas, M., Chiralt, A., \& Kenny, J. M. (2013). Effects of chitosan on the physicochemical and antimicrobial properties of PLA films. Journal of Food Engineering, 119(2), 236-243. https://doi.org/10.1016/j.jfoodeng.2013.05.026

Correlo, V. M., Boesel, L. F., Bhattacharya, M., Mano, J. F., Neves, N. M., \& Reis, R. L. (2005). Properties of melt processed chitosan and aliphatic polyester blends. Materials Science and Engineering a-Structural Materials Properties Microstructure and Processing, 403(1-2), 57-68. https://doi.org/10.1016/j.msea.2005. 04.055

Domard, A., \& Rinaudo, M. (1983). Preparation and characterization of fully deacetylated chitosan. International Journal of Biological Macromolecules, 5(1), 49-52. https://doi.org/10.1016/0141-8130(83) 90078-8

Dutta, P. K., Tripathi, S., Mehrotra, G. K., \& Dutta, J. (2009). Perspectives for chitosan based antimicrobial films in food applications. Food Chemistry, 114(4), 1173-1182. https://doi.org/10.1016/j.foodchem.2008.11.047

Epure, V., Griffon, M., Pollet, E., \& Avérous, L. (2011). Structure and properties of glycerol-plasticized chitosan obtained by mechanical kneading. Carbohydrate Polymers, 83(2), 947-952. https://oi.org/10.1016/ j.carbpol.2010.09.003

Hernandez-Izquierdo, V. M., \& Krochta, J. M. (2008). Thermoplastic processing of proteins for film formation: A review. Journalof Food Science, 73(2), 30-39. https://doi.org/10.1111/j.1750-3841.2007.00636.x

Leceta, I., Guerrero, P., \& de la Caba, K. (2013). Functional properties of chitosan-based films. Carbohydrate Polymers, 93(1), 339-346. https://doi.org/10.1016/j.carbpol.2012.04.031

\section{Copyrights}

Copyright for this article is retained by the author(s), with first publication rights granted to the journal.

This is an open-access article distributed under the terms and conditions of the Creative Commons Attribution license (http://creativecommons.org/licenses/by/4.0/). 